\title{
Transnational Cooperation in Europe: The Example of Integrated Spatial and Transport Development along the Hamburg- Athens Corridor
}

\author{
By Ana Peric ${ }^{*}$ \\ Bernd Scholl
}

\begin{abstract}
As defined by the European Commission, the Hamburg-Athens Corridor is one of the most significant European transportation axes. It is one of the key areas for international investments in transportation hubs and lines; however, it coincides with the Western Balkan and Eastern Mediterranean migration routes. Global issues, hence, make the Hamburg-Athens Corridor a key strategic area in Europe. As paper presents the results of the initial phase of the European project on transnational cooperation in the domain of integrated spatial and transport development along the Hamburg-Athens Corridor, the overview of the results is given as follows. Firstly, the paper presents the main trade, economic and demographic statistic indicators in order to clarify the strategic position of Europe against transcontinental relations. Secondly, major findings on infrastructural, economic and demographic parameters relevant for the countries along the Hamburg-Athens Corridor are indicated. Finally, a close interaction between transport and spatial development in the cities along the corridor is briefly presented. Such a multi-scalar perspective gives a hint on the dynamics of transnational cooperation (in broader terms), as well as the cooperation process among many stakeholders from various domains, mainly transportation and spatial planning (in narrow terms).
\end{abstract}

Keywords: Hamburg-Athens corridor, Spatial development, Transnational cooperation, Transportation.

\section{Introduction}

The Hamburg-Athens Corridor, defined as the Corridor 22 in the European Union (EU) TEN-T (Trans-European Transport Network) policy (European Communities, 2005), and as the TEN-T Orient/east-Med(iterranean) corridor within the more recent EU Core Network programme "Connecting Europe Facility" (European Commission, 2011) is a key north-south transport corridor in Europe. In its length of more than 2,000 km, it connects the ports in the north of Germany with the Adriatic and the Danube ports as well as the seaports in Thessaloniki and Athens (Figure 1).

However, the Hamburg-Athens Corridor is currently an example of

\footnotetext{
* Postdoctoral Researcher, Institute for Spatial and Landscape Development, ETH Zurich, Switzerland.

${ }^{\dagger}$ Professor, Institute for Spatial and Landscape Development, ETH Zurich, Switzerland.
} 
genuine shortcomings in various domains. Among others, it is useful to frame the research on the aspects of trade, infrastructure and demography. Thus, in terms of economy, the Hamburg-Athens corridor runs through the states with traditionally low economic performances in comparison with the developed Western European countries. There is also a significant lack of efficient infrastructural network, which is seen in numerous missing links and bottlenecks. Finally, the corridor nowadays coincides with the so-called migration routes (Western Balkan and Eastern Mediterranean branch).

Figure 1. Overview Map of the Project Perimeter

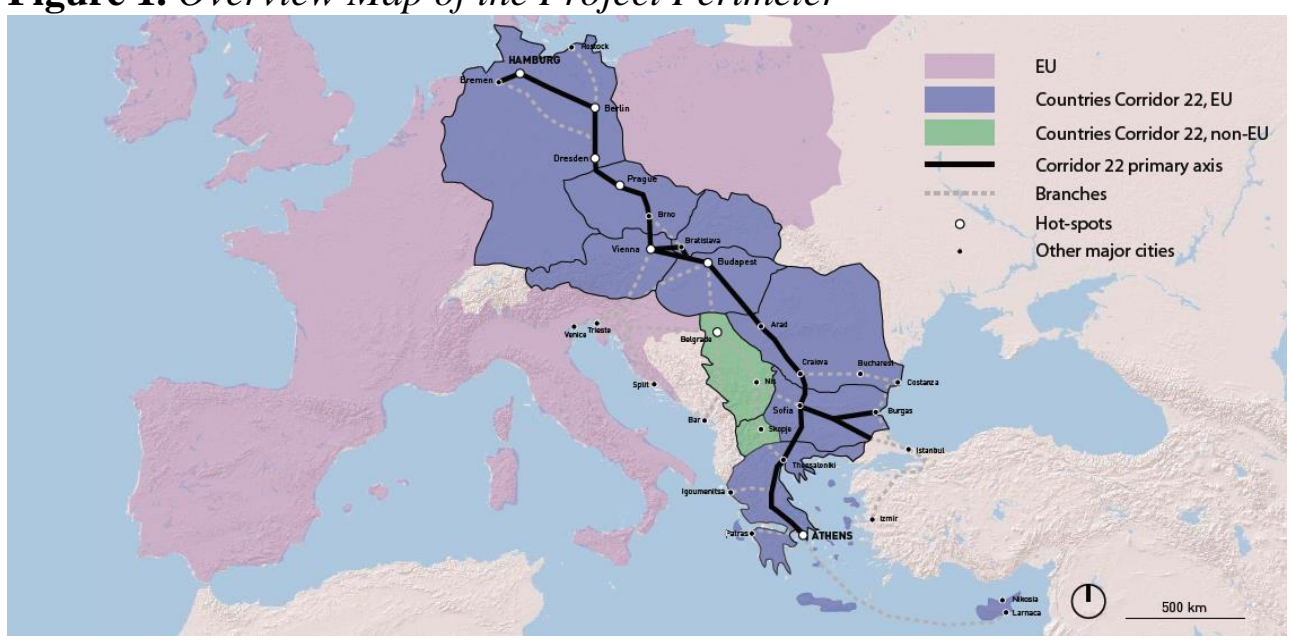

Source: ETH/IRL documentation.

Previously mentioned challenges served as a starting point of initiation a new research project titled "Spatial and Transport Development in European Corridors: Example Corridor 22, Hamburg-Athens", being conducted currently by the German Academy for Spatial Research and Planning (ARL) from Hanover. ${ }^{1}$ The project is focused on a need for sustainable development along the corridor, as well as the opportunities for the development of the respective countries. More precisely, the project aims at developing a comprehensive strategic programme for the future integrated spatial and transport development of the entire corridor. As a matter of questioning the large-scale sustainable infrastructure policy, the project is particularly focused on the rail transport (both passenger and freight), brownfield regeneration as a mechanism of exploiting the urban development potential, as well as on the advanced methods and tools for a better institutional cooperation.

The paper is structured as follows. Firstly, a brief explanation on the importance of integrated development is given. This is done by taking into account the multidimensional and multi-scalar nature of corridors. The

\footnotetext{
${ }^{1}$ The three-year ARL project "Spatial and Transport Development in European Corridors: Example Corridor 22, Hamburg-Athens" officially started in November 2015. The International Working Group (IAK) of experts gathered around the project comprises 13 participants mainly from transportation and spatial planning field, working in various domains - public offices, NGOs and academic institutions. The roles of the project coordinator and the project leader are assigned to the authors of this paper, respectively.
} 
overview is followed by a multi-level analysis - presenting and commenting the selected indicators (trade, infrastructure, economy, demography) at various levels: global, European and local. The preliminary project outcomes are briefly summarized at the end of the paper.

\section{Why do we Need Integrated Development?}

At the very beginning, it is important to briefly describe the main terms relevant for the project topic. Firstly, it is important to clarify what is actually understood as a corridor. Namely, a corridor is a bundle of infrastructure and adjacent settlements and landscapes linking regions spread over a certain physical space (cf. Witte, 2014). From such a definition, it is clear that infrastructure development cannot be considered without taking into account the spatial dimension. In other words, spatial and infrastructural development can be considered "two sides of the same coin" (Scholl, 2012). Moreover, due to its axial nature, the issue of corridor development usually goes beyond the national borders (Scholl, 2016). The main indicators assigned to the topic of corridor development are: 1) mode (road, rail and inland waterway), and 2) scope (freight and passenger) (Priemus and Zonnenveld, 2003).

Two main factors determining the approach used when dealing with corridor development, are its multidimensional and multi-scalar nature (Chapman, Pratt, Larkham and Dickins, 2003). Multidimensional nature refers to various dimensions appropriate for further analysis, such as: 1) infrastructure (physical and organisational infrastructure), 2) space (functions and morphology), 3) governance (politics and institutions), and 4) economy (finance and market conditions). Although there can be difficulties in combining various aspects to gain the synergetic developmental effects, the improvement of its spatial and infrastructural dimension certainly have no negative impact on other two factors. When it comes to the multi-scalar nature of corridors, it is logical to mention three main levels of observation: 1) transnational, 2) regional, and 3) local.

Having in mind the current shortcomings in various domains addressing the topic of corridor development, it is important to clarify the need for integration of different perspectives of various stakeholders:

- In the policy programmes - there is still a sectorial, one-dimensional approach, i.e. without taking into account compatible factors contributing to the synergy

- In the administration - there is a lack of appropriate institutions and governance structures, and, more importantly, their joint collaboration on a topic of corridor development

- In the practice - there is still a clear persistence of bottlenecks at various forms and levels

- In the academia - there is an absence of specific knowledge with a constant fragmentation of the academic debate. 
In sum, there is an absence of a holistic approach to the problem. Hence, we need to develop an integrated, multidisciplinary and multi-sectorial approach to challenging issues extending through various fields. The ARL project tries to make a small step in bridging this gap.

\section{Global Trends and their Effect on European Development}

Transnational issues like corridor development never depend only on the conditions given by the states through which the corridor passes by. Moreover, the corridors important for the entire continent - in terms of Europe's further growth, development and sustainability, are always affected by the global flows and tendencies. In the following lines, the overview of the indicators (trade, economy and demography) at the global scale are presented in order to elucidate its impact on the Hamburg-Athens Corridor.

\section{Trade}

Commercial (i.e. goods traded, not services nor capital transfers and foreign investments) activity has experienced $0.3 \%$ growth rate worldwide from the year-to-year data available (2013-2014) amounting to 38 trillion USD in total value. As Figure 2 presents, a total commercial trade experienced a decline in activity during the crisis years both world- and region wise (World Trade Organization, 2014; Acebillo, 2015). The fast recovery (21\% from 2009-2010) coincides with the fast growth of the after crisis years. Trade growth from 2011 has remained quite constant at an average annual rate of $1.1 \%$ in the period 2011-2014. Other regions such as Asia and Europe have experienced a very similar growth pattern.

Within the maritime trade sector, TEU traffic is paid special attention to, as it plays a crucial role in the definition of the Corridor 22. Global containerized trade has reached 171 million of TEUs in $2014(+5.3 \%$ since 2013). Partly reflecting the recovery in the US and the improved prospects for Europe, containerized trade volumes carried on the Asia to Europe and Asia to North America routes are estimated to have increased by $7.5 \%$ and $6.3 \%$ since 2013, respectively. Reflecting a weaker import demand in Asia, trade volumes on the backhaul journeys (opposite direction) remained weak. The strongest route is once again the Asia to Europe line, carrying 15.4 million of TEUs in 2014. The second largest is the line covering Asia to North America trade with 14.7 million TEUs carried (UNCTAD, 2015; Acebillo, 2015). 
Figure 2. Commercial Trade

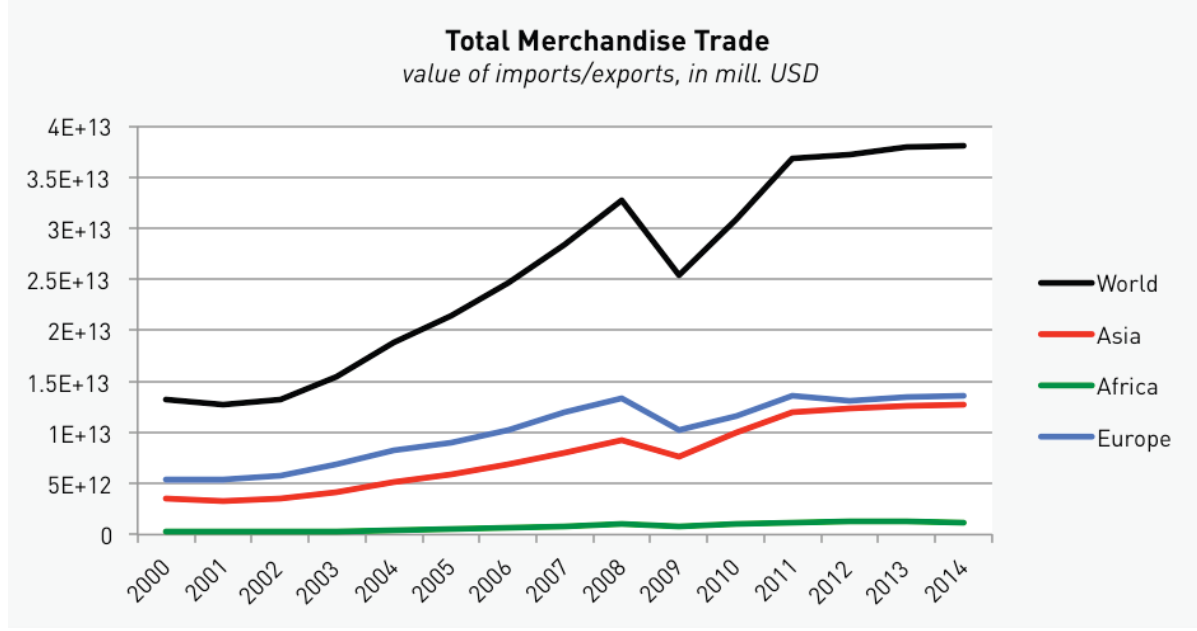

Source: Acebillo, P. 2015.

\section{Economy}

Two main aspects determine the current global economic situation: 1) the gradual slowdown in the Chinese economy, experiencing a structural transition from an investment-intensive model to a consumption-oriented one, and 2) the downturn in commodity prices triggered by weaker demand as well as over supply from the OPEC (Organization of the Petroleum Exporting Countries) members (World Bank Group 2015; Acebillo, 2015).

Figure 3. GDP Rate, Global, 2010-2020

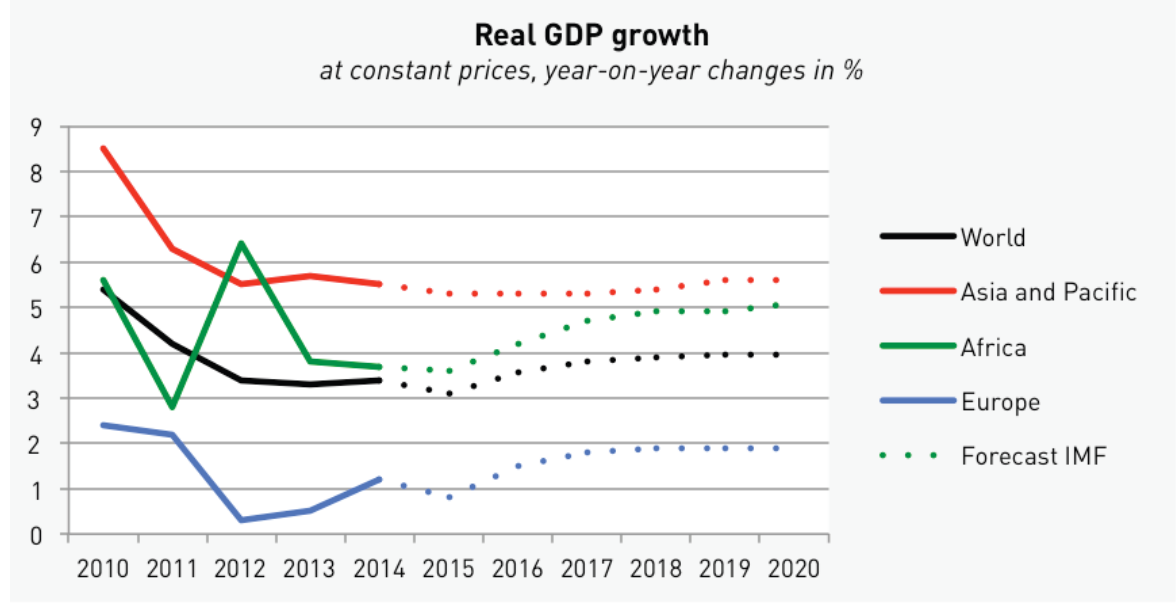

Source: Acebillo, P. 2015.

These factors are forcing the global economy to a stagnated period. As seen in Figure 3, global growth for 2015 is projected at $3.1 \%$, which is $0.3 \%$ lower than in 2014. Global GDP growth is expected to remain constant close to 4\% until 2020 (International Monetary Fund, 2015; Acebillo, 2015). In this context, advanced economies are expected to pick up slightly maintaining interest rates generally low. This is brought by a modest recovery in the Euro 
Area (from $0.9 \%$ in 2014 to $1.5 \%$ in 2015 and $1.6 \%$ in 2016) supported by lower energy prices, monetary easing from the ECB since March 2015 and the euro depreciation, falling by $11 \%$ against the US Dollar from the 1st October 2014 until the 1st October 2015. Europe is also expected to consolidate a modest growth from 2015 on. From the current $1.2 \%$ it is projected to stabilize at 1.9\% until 2020 (P.W. and C.R., 2015; Acebillo, 2015).

\section{Demography}

A further key aspect regarding trade and economic development are demographic tendencies as consumption and labour productivity induced by the living population and its age structure.

Figure 4. Total Population, Global, 2015-2060

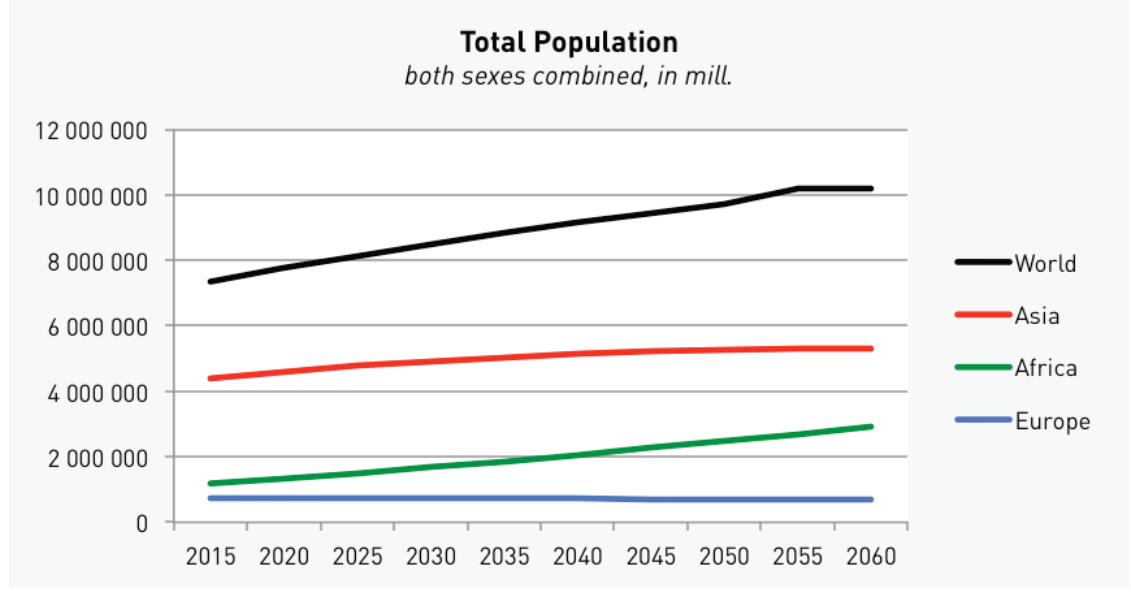

Source: Acebillo, P. 2015.

In 2015, the world population reached 7.3 billion and is projected to grow until 10.1 billion until 2050. All regions besides Europe are expected to experience demographic growth in the future. While Asia will add 896 million of people to its continent, Africa will contribute with an additional 1,700 million inhabitants to the world population. This means a growth rate of $20 \%$ and $144 \%$ from the present until 2050, respectively. In contrast to these figures, the European continent will shrink demographically by losing 50 million inhabitants, i.e. the population will decrease by $6.7 \%$ over the same period (see Figure 4) (United Nations, 2015).

\section{European Hamburg-Athens Corridor: Overview of the Current State}

The overview of the current state along the Hamburg-Athens Corridor is observed through the indicators of infrastructure, economy and demography, as follows. 


\section{Infrastructure}

Main findings with regard to the traffic overview along the HamburgAthens Corridor are explained in the following lines (Acebillo, 2015):

1) There is an asymmetry in the freight distribution through the maritime transportation mode. Sea freight is mainly concentrated in the North ports of Hamburg and Bremerhaven. At the same time, maritime passenger figures are low in Germany. In contrast to this, both in Greece and the Adriatic ports, the main flows using ports are the passengers, denoting a much more tourist-oriented economy than in the North (Figure 5).

Figure 5. Infrastructure Analysis

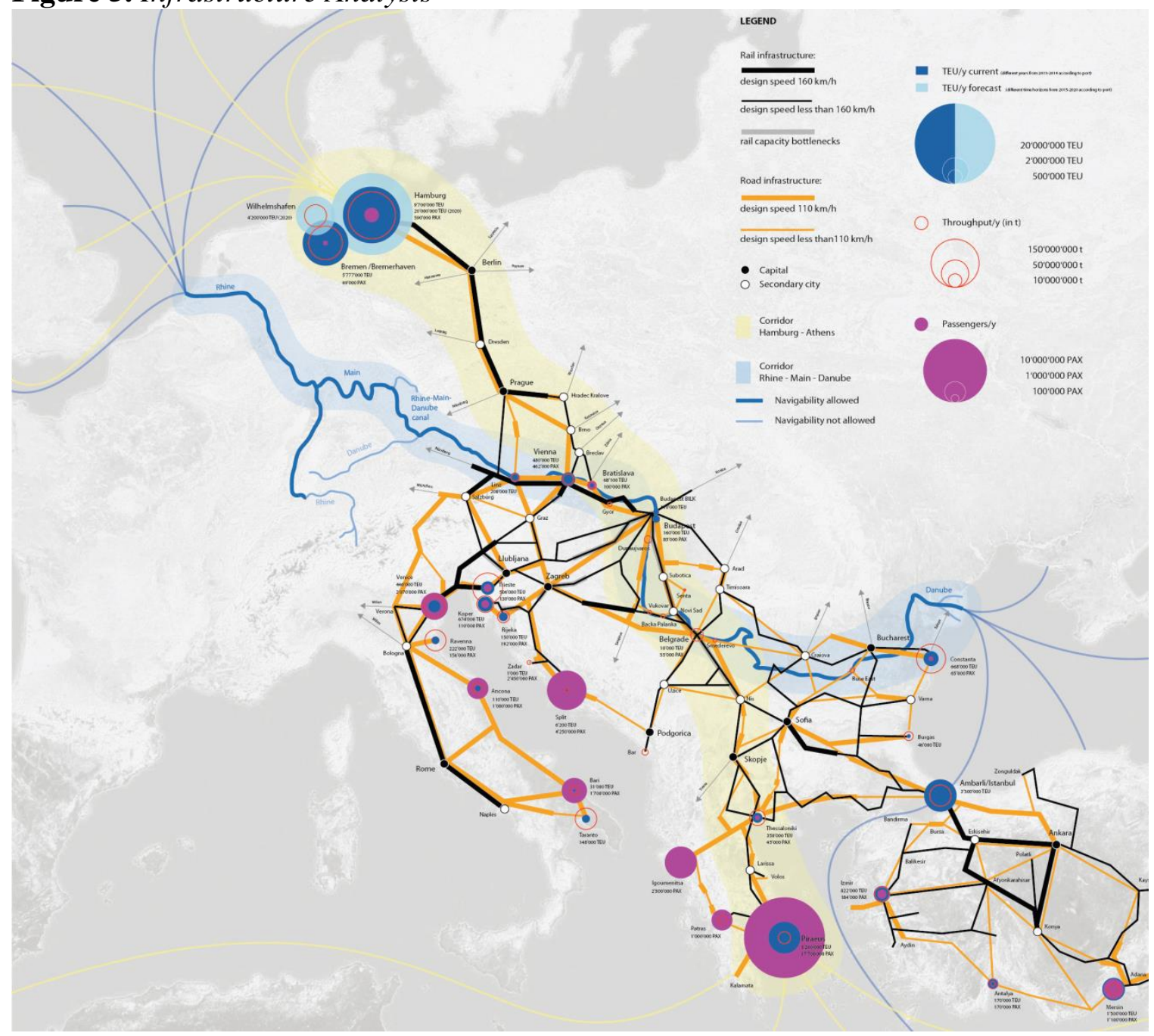

Source: ETH/IRL documentation.

2) There is unevenness in infrastructure development, reflecting the past of Eastern Europe. High-speed train lines are in operation in developed 
countries as Germany, Austria and Italy, but completely lacking in the Balkan countries. Moreover, a density in the high-level road systems is also lower in Romania and Bulgaria compared to much northern countries.

3) The Corridor 22 has a $51 \%$ lower performance than EU countries when weighting following indicators together: Imports/Exports of goods, Goods transported on rail/road, passenger transported on rail/road and rail/ road network density.

\section{Economy}

From an economic point of view, the Hamburg-Athens Corridor and its catchment area is consolidating an economic recovery after the financial crisis. In 2014, it experienced $1.36 \%$ GDP growth and is expected to keep the pace stabilizing at $2.5 \%$ until 2020 . These figures are lower than the overall global GDP but certainly better if compared to Europe. In fact, the Corridor 22 just overpassed the Europe average and is expected to maintain the trend in the next 5 years. There are considerable differences within the corridor members. In fact, only 4 out of the 11 countries did not enter the negative growth rates in the last five years. While Greece and Cyprus dropped until $-8 \%$ rates, Germany, Austria, Hungary and Bulgaria maintained their GDP figures in the positive area. As a consequence, the slowest recovery is projected to occur in Greece and Cyprus, staying in negative figures until 2016 (see Figure 6) (Acebillo, 2015).

Figure 6. GDP Rate, Regional, 2010-2020

Real GDP growth

at constant prices, year-on-year changes in \%

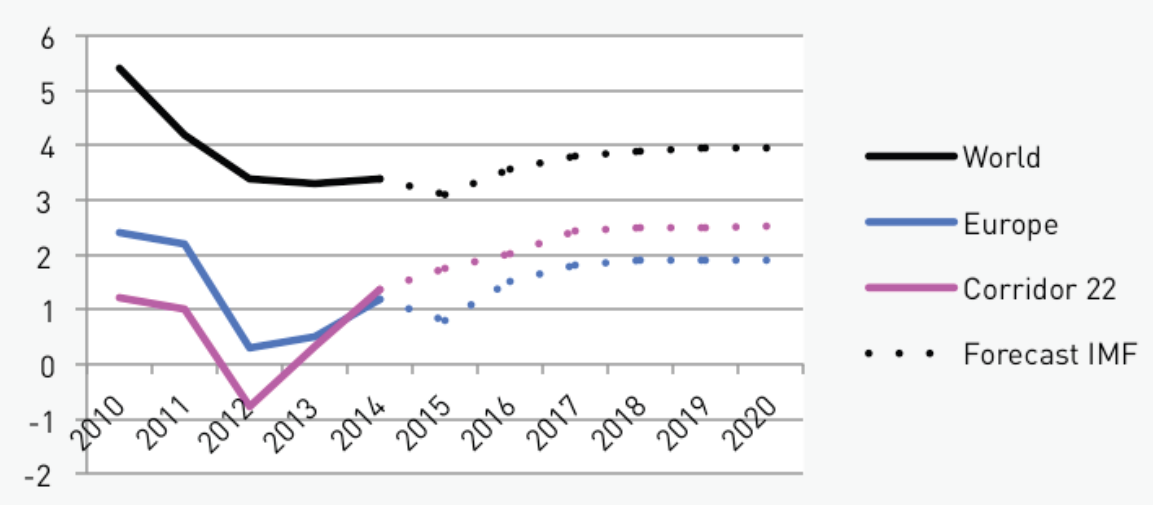

Source: Acebillo, P. 2015.

Following economic indicators were compared between the Corridor 22 countries and EU as a whole: Total GDP, GDP/capita, Purchasing Power Parity (PPP), GDP growth rate, Unemployment rate, Population density, Urban population share and Global Competitiveness index. The analysis concluded that Hamburg-Athens Corridor countries perform on average $21 \%$ lower than EU nations (Acebillo, 2015). 


\section{Demography}

Demographic figures in the region show a declining trend both in absolute terms and in labour force categories. Whereas the world will grow in absolute terms, the Corridor 22 and Europe will shrink by $15 \%$ and $7 \%$, respectively. What is more worrying, the labour force in the corridor countries is projected to downward in the coming decades stronger than in Europe. Although shrinking in the three levels (World, Europe, Hamburg-Athens Corridor), it is in the last two were the decline is more acute. If 92 million of people are now aged between 25 and 64 in the research context, it will be only 63 million in 2060. Again, global trends are reflected also in the corridor system. While old population segments will keep growing at a fast pace ( $+76 \%$ by 2060$)$, young age categories will barely maintain its share in total population $(-10 \%$ by 2060$)$ (Figure 7). Two indicators counterbalance the negative demographic prospects for the corridor: 1) a very high Life Expectancy set at 77 years (World average is 70.4), and 2) a slight upturn in Total Fertility rate from the current 1.4 children/woman to 1.7 in 2060 (Acebillo, 2015).

Figure 7. Age Categories, Hamburg-Athens Corridor, 2015-2060

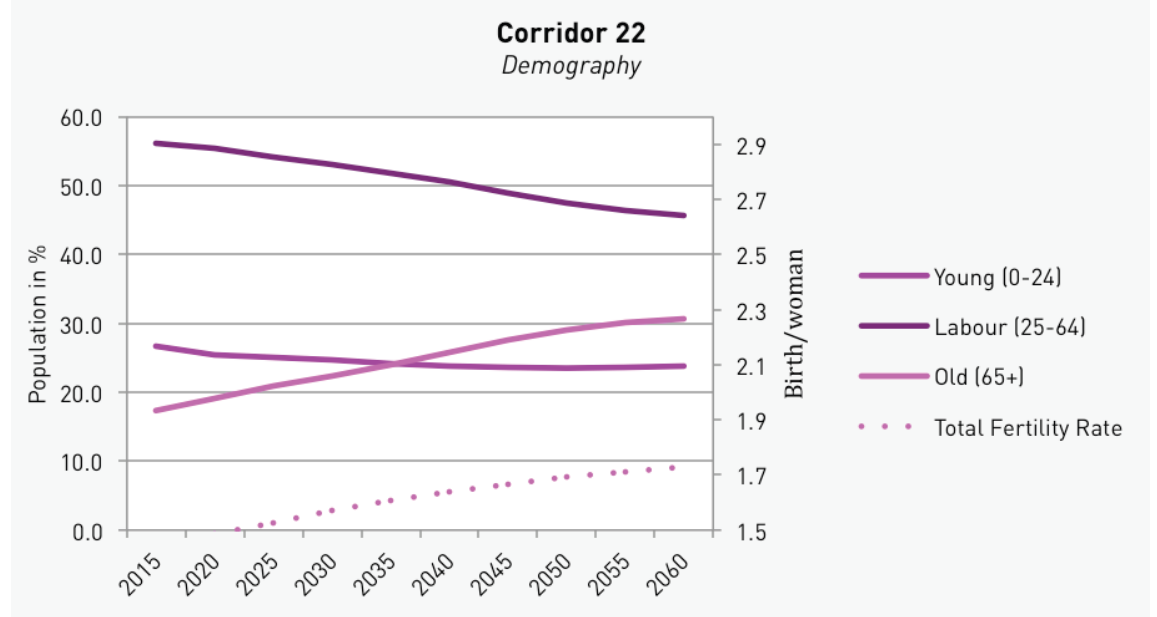

Source: Acebillo, P. 2015.

Hence, these figures urge the Hamburg-Athens Corridor and Europe authorities to incentive policies supporting natality. Moreover, immigration should be seen as an opportunity to counterbalance the shrinking European labour force and thus ease public expenditure pressure on retirement pensions (Acebillo, 2015).

\section{Identifying the Hot-Spots along the Corridor}

The local scale of the Hamburg-Athens project relates to identifying the hot-spots, i.e. places with major spatial implications of transport infrastructure development. Moreover, it is interesting to observe some 'good-practice' 
examples of integrated spatial and infrastructure development as well as more challenging case studies. The result is directed towards mutual learning finally aimed at improving the collaboration among various stakeholders with different interests.

\section{Hamburg}

The famous example of turning the port infrastructure into the high-quality urban area is the HafenCity in Hamburg. Ambitious project of the redevelopment of 157 ha is still in progress, although its major part is already implemented. In addition to the fact that recycling the obsolete port infrastructure resulted in the creation of new mixed-use neighbourhood (with 6000 homes and 45000 jobs), the HafenCity is a valuable example on how to reach both the green and high sustainability standards. More precisely, Lohsepark (i.e. the Central Park of the HafenCity) will be extended to the River Elbe. Against this background, the public spaces increase to 26 ha, while the public waterfront extends to $10.5 \mathrm{~km}$.

\section{Berlin}

Following the ideas for the development of a new Berlin railway station (opened in 2006), the project called EuropaCity was prepared for the area in the vicinity of the station, within the site once used as a fright port. The specificity of the project for central station is its relying on the idea of tradition. In other words, it was the construction on the traditional site for the future of the city. More precisely, new station is placed where one of the oldest Berlin station (Lehrter station) used to be in the past. The EuropaCity project is designed as a mixed-use quartier for the improvement of urban life -40 ha of office, residential, shopping \& leisure, and culture space.

\section{Dresden-Prague}

The German Federal State of Saxony and the Czech Republic work together to find a valid solution for a new railway route between Dresden (D) and Usti nad Labem $(\mathrm{CZ})$ not passing through the Elbe Valley, a current route. The new line Dresden-Prague is to be laid out to carry both passenger and freight traffic. The target set includes creating more capacity for European cross-border freight traffic along the north-south axis and halving the journey times of long-distance passenger trains. As this demanding project considers legal, technical and environmental aspects, the European Union is also making a financial contribution to the study.

\section{Vienna}

One of the most recent demands of how to jointly consider the topic of spatial and infrastructure development was successfully implemented in 
Viennese case study. Namely, on the area of 55 ha the new central railway station of Vienna (instead of two former dead-end stations: east and south) was opened for the public in late 2014. Due to its position in the zone of previous railway nodes it is famous as a transport hub - well connected to metro, bus and tram- lines, in the central city core. Moreover, it is certainly more than a station: it is an excellent example of how infrastructure, office, residential and green spaces work together.

\section{Budapest}

Although some of the key strategic areas for the spatial development of the Budapest metropolitan area still wait for the preliminary urban and architectural proposals and possible investments (e.g. Csepel Island), "Office Campus" project in the vicinity of the Ferencvaros Station is one of the examples that highlight the importance of boosting new development in the vicinity of rail infrastructure. New office and retail complex is to be raised at the site of the abandoned public slaughterhouse on the area of 18 ha. However, due to the global economic crises, only two of more than twenty buildings were realised until 2008.

\section{Belgrade}

In Belgrade, as a city still in a socio-spatial transition period, many challenges are set out. Finding the appropriate spatial solutions is made difficult mainly due to the insufficient collaboration of all the interested parties - usually the decisions are made on the expense of public interest. One of the striking examples of a tight cooperation between private investors (from the United Arab Emirates) and the national government is the agreement for the 'Belgrade Waterfront' project, signed in 2015. According to this, Belgrade should raise into completely unrecognisable European capital (similar to those in Hong Kong, Singapore, Dubai, etc.) thus sacrificing 90-ha area of national importance.

\section{Athens}

Athens, as a great capital of Southern Europe, does not have the so-called "culture of railway transportation". Nowadays, there are ideas for the redevelopment of the 5-ha area of main railway station in Athens, "Larissis Station", however an over-dimensioned structure (proposed by OSE - national railway company) does not follow the idea of sustainable railway development. Another example is the regeneration of the 360 ha-area of the Hellenikon airport, the old main airport of Athens, into the high-quality city quartier in the growing part of the Athens agglomeration. However, due to understandable reasons, i.e. political, financial and social crisis, all these projects still remain in the concept phase. 


\section{Conclusions}

Instead of providing the concluding remarks, the preliminary projects outcomes are defined in the following lines.

The variety of planning cultures found along the corridor and interrelated obstacles to communication, participation and cooperation can induce certain methodological challenges. Nevertheless, taking a problem-oriented approach, the experts gathered around the project analyse the corridor as a test-bed and spatial research lab, bridging the missing link between planning theory and practice. With regard to the aspired EU membership of Serbia and the recent economic downturn in Greece, the corridor could make a sustainable contribution to territorial cohesion and strengthen ties to this part of Europe. Hence, the project seeks to address political decision makers (EU, nation states), regional policy-makers, planners, practitioners and scientists by the following goals:

1. Identifying the crucial aspects for the axis development;

2. Providing scientific-based overviews at various levels (global, European, and corridor level);

3. Identifying hot-spots and bottlenecks;

4. Recommending the effective ways of collaboration;

5. Exchanging knowledge and information with the EU Corridor Platform/ Corridor Coordinator.

\section{References}

Acebillo, P. 2015. Spatial and transport development along European corridors: Strengthening the capacity of local stakeholders in transnational cooperation. Serbian Architectural Journal 7, 3, 343-366.

Chapman, D., Pratt, D., Larkham, P. and Dickins, I. 2003. Concepts and definitions of corridors: Evidence from England's Midlands. Journal of Transport Geography $11,3,179-191$.

European Commission. 2011. TEN-T Core Network Including Core Network Corridors. $\mathrm{EC}$, Brussels.

European Communities. 2005. Trans-European Transport Network - TEN-T priority axes and projects. Office for Publications of the European Communities, Luxembourg.

International Monetary Fund. 2015. World Economic Outlook October 2015 - Adjusting to Lower Commodity Prices. International Monetary Fund, Washington.

P.W. and C.R., „Getting the machines revving“, The Economist, London, March 9, 2015, accessed October 2, 2015, http://econ.st/2dUajWL.

Priemus, H. and Zonneveld, W. 2003. What are corridors and what are the issues. Introduction to special issue: the governance of corridors. Journal of Transport Geography 11, 3, 167-177.

Scholl, B. Ed. 2012. SAPONI, Spaces and Projects of National Importance. vdf Hochschulverlag, ETH Zurich, Zurich.

Scholl, B. 2016. Spatial Planning and Development in a European and Macro-regional Context. In Integrated Spatial and Transport Infrastructure Development: The Case 
of the European North-South Corridor Rotterdam-Genoa, H. Drewello and B. Scholl, Eds. Springer International Publishing Switzerland, 11-47.

UNCTAD (United Nations Conference on Trade and Development). 2015. Review of Maritime Transport 2015. United Nations Publication, Geneva.

United Nations. 2015. World Population Prospects - Key findings \& advance tables 2015 Revision. United Nations Publication, New York.

Witte, P. 2014. Does Integration Work for Corridor Development? In Conference paper (Utrecht), http://bit.ly/2dNXAFr.

World Bank Group. 2015. Global Economic Prospects June 2015 - The Global Economy in Transition. The World Bank, Washington.

World Trade Organization. 2014. World Trade Report 2014 - Trade and development: recent trends and the role of the WTO. World Trade Organization, Geneva. 
